\title{
FREQUENCY TO NON-COMPLIANCE TO ORAL IRON THERAPY IN PREGNANCY AND COMMON FACTORS LEADING TO IT
}

\author{
Qandeela Irum Qureshi ${ }^{1}$, Muhammad Basit Hashmi ${ }^{2}$, Ahmed Siddique Ammar ${ }^{3}$, Shehrbano Khattak ${ }^{4}$, \\ Sahar Saeed ${ }^{5}$, Zahra Sattar ${ }^{6}$, Hirra Alavi ${ }^{7}$
}

\section{ABSTRACT:}

\section{OBJECTIVES:}

The objective of this study was to determine frequency of non-compliance to oral iron therapy in pregnancy and common factors leading to it.

\section{METHODOLOGY:}

It was a cross-sectional study done in the Department of Obstetrics and Gynecology of Lady Willington Hospital Lahore, Pakistan. The duration of this study was six months i.e., $3^{\text {rd }}$ October 2019 to $2^{\text {nd }}$ March 2020. All antenatal patients between ages of 18 to 45 years presented in the obstetrics outdoors or admitted in the ward were included in this study. A total of 245 patients were included in this study by consecutive non-probability sampling. Patients with gynecological problems, patients dependent on others for their medication cost, patients with psychiatric illness or physical disability were excluded. Post stratification Chi-square test was applied keeping P-value $\leq 0.05$ as significant

\section{RESULTS:}

Among 245 patients, mean age was $27 \pm 2.16$ years. Iron supplement used by 245 patients was analyzed as 159 (65\%) patients had used the iron supplement while 86 (35\%) patients didn't use iron supplements (P-value 0.001). Iron supplement used by 245 patients was analyzed and only 93 (38\%) patients had used the iron supplement while $152(62 \%)$ patients didn't use iron supplements.

\section{CONCLUSION:}

The coverage of antenatal iron and folic acid supplements is very low in the surveyed districts of Pakistan due to lack of parental education and older aged women belonging to poor households.

KEYWORDS: Non-compliance, Oral iron, Pregnancy, Gynecology, Neonate, Mother

How to cite this article:

Q QI, Muhammad BH, Ammar AS, Khattak S, Saeed S, Sattar Z, Alavi H. Frequency to Non-Compliance to Oral Iron Therapy in Pregnancy and Common Factors Leading to it. J Gandhara Med Dent Sci. 2022;9(1): 58-63

https://doi.org/10.37762/jgmds.9-1.175

\section{Correspondence:}

'Qandeela Irum Qureshi, Senior Registrar Gynecology, DHQ

Teaching Hospital, DI Khan

(8): +92-346-8985503

$凶$ : qindeel_irum@hotmail.com

${ }^{2}$ Senior Registrar Pediatrics, DHQ Teaching Hospital, DI Khan

'Senior Registrar General Surgery, East Surgical Ward MAYO

Hospital, Lahore

${ }^{4}$ Lecturer Bio Chemistry, King Edward Medical University, Lahore

'Senior Registrar General Surgery, East Surgical Ward MAYO

Hospital, Lahore

${ }^{6}$ Senior Registrar General Surgery, East Surgical Ward MAYO

Hospital, Lahore

${ }^{7}$ Senior Registrar Plastic Surgery, East Surgical Ward MAYO

Hospital, Lahore

\section{INTRODUCTION:}

Anemia is a medical condition in which the carrying capacity of red blood cells for oxygen becomes inadequate to fulfill the physiological requirements of the body. It may cause very severe health problems during pregnancy and may have severe side effects on both maternal and fetal outcomes. The World Health Organization defines anemia as the concentration of hemoglobin $<11 \mathrm{~g} / \mathrm{dl}$ or hematocrit $<37 \%$ during pregnancy ${ }^{1}$. All over the world, $42 \%$ of females of reproductive age have anemia and about $50 \%$ of these females have 
anemia because of deficiency of iron content in blood $^{3}$. In Pakistan, it has been estimated that anemia in pregnancy is observed in $51 \%$ pregnant females. In Pakistan oral iron supplements are distributed by Maternal and Child Health $(\mathrm{MCH})$ services through primary health care facilities including lady health workers. One of the main reasons for iron supplements programs failure is non-compliance ${ }^{2}$. In Pakistan, it has been estimated that anemia in pregnancy is observed in 51\% pregnant females. Maternal anemia is significantly associated with high maternal mortality rate and poor obstetric outcomes ${ }^{9}$. A trial in China showed $47 \%$ reduction in neonatal mortality when pregnant women were given antenatal oral iron folic acid supplements ${ }^{4}$. The World Health Organization recommends daily prophylactic doses of oral iron supplements especially in prevalent areas ${ }^{23}$. The World Health Organization defines noncompliance as the degree to which a person "s behavior to take the medicines, following the diet or accomplishing the changes in lifestyle, matches with the agreed recommendation from the health care provider. Several factors play significant roles in whether the person fulfills their treatment and pregnancy offers the exclusive encounter as noncompliance can pose many serious health issues, not only to the mother but also the fetus ${ }^{15}$. The overall non-compliance rate in pregnancy is predicted as $43 \%$ in Pakistan. In comparison to other countries, the rate of non-compliance to iron folic acid supplements is found lowest in Pakistan $(40 \%)^{11}$. In one study conducted in Nigeria compliance for oral iron was found to be $65.9 \%{ }^{22}$. In a study in Peru compliance was found to be $79 \%$. In south India compliance for iron folic acid was reported to be $64.7 \%$. Common factors leading to non-compliance to oral iron therapy include illiteracy $(70.3 \%)$, living in rural areas $(64.3 \%)$, maternal age of 45 years and above (81.4\%), lowest socio-economic status $(\mathbf{7 4 . 7 \% )}$ and poor health education $(73.2 \%)^{8}$. As most of the studies are from developed countries and limited data exists regarding factors leading to non-compliance to oral iron therapy in Pakistan, it is obvious that there is a lot of social difference including literacy rate, economic, cultural and environmental differences between developed countries and our region. Hence, we expect that the factors affecting compliance to oral iron therapy may be different in our community than the developed countries. Therefore, we designed this study to identify the factors responsible for non-compliance to oral iron therapy in antenatal patients in our community.

\section{METHODOLOGY:}

It was an observational cross-sectional study conducted in the Obstetrics and Gynecology Department of Lady Willington Hospital Lahore, which is the teaching hospital of King Edward Medical University Lahore Pakistan. The duration of the study was six months i.e., $3^{\text {rd }}$ October 2019 to $2^{\text {nd }}$ March 2020. A total of 245 patients were included in this study using $64.3 \%$ proportion of common factors leading to non-compliance to oral iron therapy in pregnancy, 95\% confidence level, $6 \%$ margin of error with the help of WHO software ${ }^{7}$ Inclusion criteria included all consecutive pregnant female patients between the ages of 18 to 45 years presented to obstetrics outdoors or already admitted in gynae ward and labor room. Exclusion criteria include patients with other gynecological problems, patients dependent on others for their medication cost, patients with psychiatric illness or physical disability and those patients who were prescribed injectable iron supplements by a qualified medical specialist. Informed verbal consent was taken after explaining to the patients the purpose and benefits of the study and with the permission that the study was only for data review and publication. All the information taken from the patient was recorded on a predesigned proforma on the spot. Data was analyzed by SPSS version 26. Mean \pm SD was calculated for numerical variables like age, gravid, para and duration since live birth. Frequency in percentage was calculated for categorical variables like iron supplements used, period of gestation and common factors (affordability, health literacy, resident). Common factors were stratified among age, period of gestation and iron supplements used. Post stratification Chi-square test was applied keeping $\mathrm{P}$-value $\leq 0.05$ as significant. All the results were presented in the form of tables.

\section{RESULTS:}

Among 245 patients the mean age was $27 \pm 2.16$ years. The age groups of patients, literacy level, gravid status, parity status and interpregnancy interval are described in Table 1. Duration since live birth 245 patients was analyzed as $172(70 \%)$ patients have their last delivery $\leq 3$ years while 73 $(30 \%)$ patients have their last delivery $>3$ years. Mean duration was $3 \pm 1.77$ years (Table 1). Iron supplement used by 245 patients was analyzed and only $93(38 \%)$ patients had used the iron supplement while $152(62 \%)$ patients didn't use iron supplements. Non-affordability, knowledge of tablets prescribed, period of gestation and 
compliance to oral iron therapy during pregnancy

is mentioned in Table 2.

Table 1: Characteristics of Patients

\begin{tabular}{|l|c|c|}
\hline Age Groups & Frequency & Percentage \\
\hline 18-25 Years & 81 & $33 \%$ \\
\hline 26-35 Years & 103 & $42 \%$ \\
\hline 36-45 Years & 61 & $25 \%$ \\
\hline Educated & 54 & $22 \%$ \\
\hline Uneducated & 191 & $78 \%$ \\
\hline Primary Gravida & 78 & $32 \%$ \\
\hline Multigravida & 167 & $68 \%$ \\
\hline Primipara & 93 & $38 \%$ \\
\hline Multipara & 152 & $62 \%$ \\
\hline Interpregnancy Interval & & $70 \%$ \\
\hline$\leq 3$ Years & 172 & $30 \%$ \\
\hline$>3$ Years & 73 & \\
\hline
\end{tabular}

Primary Gravida=pregnant for $1^{\text {st }}$ time (fetus alive or dead) or delivered single alive baby in the past, Multigravida=pregnant for more than 1 time in the past (fetus alive or dead). Primary Parous $=$ female who delivered 1 alive baby, Multiparous=female who delivered more than 1 alive babies.

Table 2: Factors Affecting Non-Compliance

\begin{tabular}{|c|c|c|c|c|}
\hline & & Frequency & Percentage & P-Value \\
\hline \multirow{2}{*}{ Non-Affordability } & Yes & 159 & $65 \%$ & \multirow[t]{2}{*}{0.015} \\
\hline & No & 86 & $35 \%$ & \\
\hline \multirow{2}{*}{$\begin{array}{l}\text { Knowledge About Oral Iron } \\
\text { Supplements }\end{array}$} & Yes & 37 & $15 \%$ & \multirow[t]{2}{*}{0.001} \\
\hline & No & 208 & $85 \%$ & \\
\hline \multirow{3}{*}{ Period of Gestation } & $1^{\text {st }}$ Trimester & 56 & $23 \%$ & \multirow[t]{3}{*}{0.08} \\
\hline & $2^{\text {nd }}$ Trimester & 76 & $31 \%$ & \\
\hline & $3^{\text {rd }}$ Trimester & 113 & $46 \%$ & \\
\hline \multirow{2}{*}{ Complaint to Therapy } & Yes & 93 & $38 \%$ & \multirow[t]{2}{*}{0.001} \\
\hline & No & 152 & $62 \%$ & \\
\hline
\end{tabular}

\section{DISCUSSION :}

In this study the compliance to use antenatal iron and folic acid supplements was low with only $38 \%$ $(n=93)$ of women reported consumption of antenatal iron and folic acid supplements during their pregnancy. In our study only $22 \%(\mathrm{n}=54)$ of females were literate. In a study done in Vietnam it was estimated that a total of $73 \%$ of literate women reported high compliance when compared with women who were not literate who showed a $50 \%$ of compliance $^{18}$. Almost similar results are stated in a study done in Toronto which shows compliance is better in educated pregnant females as compared to uneducated pregnant females ${ }^{12}$. This shows that educated pregnant females responded well to iron and folic acid supplements as compared to uneducated ones. In our study, a substantial majority of women $46 \%$ initiated the supplements in their third trimester of pregnancy, with an average initiation in the fifth month of pregnancy. A study done by Larson et al showed almost similar results that pregnant females get more attention from doctors in their third trimester ${ }^{14}$. Many factors are responsible for this attitude. As the size of the uterus grows more in the third trimester and the growth needs of the baby increase rapidly, it takes more nutrition from the mother and hence weakness, fatigue is more prominent in the third trimester ${ }^{16}$. Only $15 \%$ of patients in our study had the knowledge of prescribed tablets while $85 \%$ of patients had no knowledge of prescribed tablets. This is because of the low education level of females in rural areas of Pakistan. In a study done in India, the socioeconomic status of Asian women living in rural areas is very poor and the majority of them are uneducated. The only health care service they have is a small dispensary that is run by a nondoctor paramedic. In a study done by Thomas et $\mathrm{Al}$, the miscarriage rate is about $14 \%$ in rural areas of south Punjab of Pakistan where major health services are not available ${ }^{20}$. According to a Pakistan demographic and health survey done in 2012-2013, only $45 \%$ of pregnant women consumed antenatal 
iron folic acid supplements during their pregnancy, which is further lowered to $39 \%$ in rural areas. This level is highest in Islamabad and lowest in Balochistan province. In comparison to other countries the usage of iron folic acid supplements is lowest in Pakistan that is $40 \%$ while noncompliance to take iron and folic acid supplements is reported to be $58 \%$. Common factors leading to non-compliance to oral iron therapy are illiteracy $(70.3 \%)$, living in rural areas $(64.3 \%)$, maternal age 45 and above $(81.4 \%)$, belonging to lowest socioeconomic status $(74.7 \%)$, poor health literacy $(73.2 \%)^{13}$. The results of our study showed that illiterate females had higher chances of noncompliance to iron and folic acid supplements during the pregnancy. The results are consistent with previous surveys conducted in South Asia or in other continents, which testified a significant association between low education statuses. This is because educated females have more access to the information regarding health during pregnancy, which improves their apprehension about their pregnancy and health of their neonate and also the utilization of antenatal care services, as compared to the illiterate females ${ }^{19}$. In our study, females aged 45 years or more are also recognized as an independent risk factor for non-compliance to antenatal iron and folic acid supplementation. Surveys conducted in Pakistan, India, Nepal and Bangladesh have also found similar results with higher rates of older aged females not taking antenatal iron and folic acid supplementation as compared to younger females ${ }^{6}$. Many surveys observed young age females as the risk factor for non-compliance of antenatal iron and folic acid supplementation. In developing countries, females of old age have more knowledge of pregnancy and child-birth and usually they do not feel the iron and folic acid supplements needed in pregnancy as they did not take these in previous pregnancies ${ }^{17}$. In contrast to that, one study found that the high sociodemographic status could be a risk factor for non-compliance of iron and folic acid supplementation in pregnancy. In developing countries, females belonging to poor socio demographic status normally don ${ }^{e t}$ use antenatal care services because of their restricted resources ${ }^{5}$. In Pakistan, the rate of utilization of antenatal care from health care professionals is $73 \%$ in pregnant females, which could lead to less access to the antenatal iron and folic acid supplements ${ }^{10}$. Another study showed that in developing countries, limited access of pregnant females to antenatal care is the major cause for non-compliance to the iron and folic acid supplements and because of this reason, World
Health Organization focused on antenatal care which is composed of four visits in pregnancy instead of previous schedules of visits in every month and to dispense of iron and folic supplements to all pregnant females at each visit ${ }^{21}$.

\section{LIMITATIONS:}

There are certain limitations to the study as well. The sample size of the study is very small and studies with large sample sizes are needed to extract more information regarding the real nature of the problem in Pakistan. Also, it is a single center study. More studies in high volume centers are needed.

\section{CONCLUSION:}

The compliance of antenatal iron and folic acid supplements by pregnant females is very low in the surveyed districts of Pakistan and this is due to the lack of parental education, old aged women belonging to poor socioeconomic status and lack of antenatal care services. All these factors were significantly associated with non-use of these supplements. The results of this study highlighted the serious need to improve the efforts, which will target the pregnant ladies by successful coverage of antenatal care to increase the use of iron and folic acid supplements during pregnancy in Pakistan.

\section{CONFLICT OF INTEREST: None}

\section{FUNDING SOURCES: None}

\section{REFERENCES:}

1. Abdulrehman J, Lausman A, Tang GH, Nisenbaum R, Petrucci J, Pavenski K, et al. Development and implementation of a quality improvement toolkit, iron deficiency in pregnancy with maternal iron optimization (IRON MOM): a before-andafter study. PLoS Med. 2019;16(8):e1002867.

2. Ajepe AA, Okunade KS, Sekumade AI, Daramola ES, Beke MO, Ijasan O, et al. Prevalence and foetomaternal effects of iron deficiency anaemia among pregnant women in Lagos, Nigeria. PLoS ONE. 2020;15(1):e0227965.

3. Asadi N, Vafaei H, Kasraeian M, Yoosefi S, Faraji A, Abbasi L. Effects of prophylactic iron supplementation on outcome of nonanemic pregnant women: a non-randomized clinical trial. J Chin Med Assoc. 2019;82(11):840-4. 
4. Ba DM, Ssentongo P, Kjerulff KH, Na M, Liu G, Gao X, et al. Adherence to iron supplementation in 22 Sub-Saharan African countries and associated factors among pregnant women: a large population-based study. Curr Dev Nutr. 2019;3(12):nzz120.

5. Brannon PM, Taylor CL. Iron supplementation during pregnancy and infancy: uncertainties and implications for research and policy. Nutrients. 2017;9(12):1327.

6. Habib MA, Raynes-Greenow C, Soofi SB, Ali N, Nausheen S, Ahmed I, et al. Prevalence and determinants of iron deficiency anemia among non-pregnant women of reproductive age in Pakistan. Asia Pac J Clin Nutr. 2018;27(1):195-203.

7. Vázquez LI, Arija V, Aranda N, Aparicio E, Serrat N, Fargas F, et al. The effectiveness of different doses of iron supplementation and the prenatal determinants of maternal iron status in pregnant Spanish women: ECLIPSES study. Nutrients. 2019;11(10):2418.

8. Inca-Caxi V, Munares-García O. Factors associated with adherence to iron supplements in pregnant women attended at a health center in Cañete, Peru. Int J Matern Fetal Health. 2020;5(1):3-10.

9. Iqbal S, Ekmekcioglu C. Maternal and neonatal outcomes related to iron supplementation or iron status: a summary of meta-analyses. J Matern Fetal Neonat Med. 2019;32(9):1528-40.

10. Kessani L, Kumar R, Rathore A, Khalid R. Associated factors and compliance with iron-folic acid therapy among pregnant women of Karachi, Pakistan. Rawal Med J. 2018;43(2):319-23.

11. Khan GN, Ariff S, Kureishy S, Sajid M, Rizvi A, Garzon C, et al. Effectiveness of wheat soya blend supplementation during pregnancy and lactation on pregnancy outcomes and nutritional status of their infants at 6 months of age in Thatta and Sujawal districts of Sindh, Pakistan: a cluster randomized-controlled trial. Eur J Nutr. 2021;60:781-9.

12. Larson LM, Phiri KS, Pasricha SR. Iron and cognitive development: what is the evidence?. Ann Nutr Metab. 2017;71(Suppl 3):25-38.

13. Mahmood T, Rehman A, Tserenpil G, Siddiqui F, Ahmed M, Siraj F, et al. The association between iron-deficiency anemia and adverse pregnancy outcomes: a retrospective report from Pakistan. Cureus. 2019;11(10):e5854.

14. Milman N, Taylor CL, Merkel J, Brannon PM. Iron status in pregnant women and women of reproductive age in Europe. Am J Clin Nutr. 2017;106(Suppl_6):1655S$62 \mathrm{~S}$.

15. Miranda VI, Santos IS, Silveira MF, Silveira MP, Pizzol TD, Bertoldi AD. Validity of patient-reported anemia and therapeutic use of iron supplements during pregnancy: 2015 Pelotas (Brazil) birth cohort. Cad Saude Publica. 2018;34(6):e00125517.

16. Okam MM, Koch TA, Tran M. Iron supplementation, response in irondeficiency anemia: analysis of five trials. Am J Med. 2017;130(8):991.e1-e8.

17. Parisi F, Berti C, Mandò C, Martinelli A, Mazzali C, Cetin I. Effects of different regimens of iron prophylaxis on maternal iron status and pregnancy outcome: a randomized control trial. J Matern Fetal Neonat Med. 2017;30(15):1787-92.

18. Symington EA, Baumgartner J, Malan L, Wise AJ, Ricci C, Zandberg L, et al. Maternal iron-deficiency is associated with premature birth and higher birth weight despite routine antenatal iron supplementation in an urban South African setting: the NuPED prospective study. PLoS ONE. 2019;14(9):e0221299.

19. Tang L, Lee AH, Yau KK, Hui YV, Binns CW. Consumption of dietary supplements by Chinese women during pregnancy and postpartum: a prospective cohort study. Matern Child Nutr. 2017;13(4):e12435.

20. Thomas MS, Demirchyan A, Khachadourian V. How effective is iron supplementation during pregnancy and childhood in reducing anemia among 6-59 months old children in India?. Front Public Health. 2020;8:234.

21. Rashid H, Saleem S, Babar KM, Mahmood $\mathrm{K}$, Younis H, Maheen S. Compliance of iron supplementation during pregnancy and factors effecting compliance. Prof Med J. 2019;26(12):2128-34.

22. Wilson RL, Gummow JA, McAninch D, Bianco-Miotto T, Roberts CT. Vitamin and mineral supplementation in pregnancy: evidence to practice. J Pharm Pract Res. 2018;48(2):186-92. 
23. Yang J, Kang Y, Cheng Y, Zeng L, Shen $\mathrm{Y}$, Shi $\mathrm{G}$, et al. Iron intake and iron status during pregnancy and risk of congenital heart defects: a case-control study. Int $\mathrm{J}$

Cardiol. 2020;301:74-9.

\section{CONTRIBUTORS}

1. Qandeela Irum Qureshi - Concept \& Design; Data Acquisition; Data Analysis/Interpretation; Drafting Manuscript; Critical Revision; Supervision; Final Approval

2. Muhammad Basit Hashmi - Concept \& Design; Data Acquisition; Data Analysis/Interpretation; Drafting Manuscript; Critical Revision; Supervision; Final Approval

3. Ahmed Siddique Ammar - Concept \& Design; Data Acquisition; Data Analysis/Interpretation; Drafting Manuscript; Critical Revision; Supervision; Final Approval

4. Shehrbano Khattak - Concept \& Design; Data Acquisition; Data Analysis/Interpretation; Drafting Manuscript; Critical Revision; Supervision; Final Approval

5. Sahar Saeed - Concept \& Design; Data Acquisition; Data Analysis/Interpretation; Drafting Manuscript; Critical Revision; Supervision; Final Approval

6. Hirra Alavi - Concept \& Design; Data Acquisition; Data Analysis/Interpretation; Drafting Manuscript; Critical Revision; Supervision; Final Approval

LICENSE: JGMDS publishes its articles under a Creative Commons Attribution Non-Commercial Share-Alike license (CC-BY-NC-SA 4.0). COPYRIGHTS: Authors retain the rights without any restrictions to freely download, print, share and disseminate the article for any lawful purpose. It includes scholarly networks such as Research Gate, Google Scholar, LinkedIn, Academia.edu, Twitter, and other academic or professional networking sites. 